\title{
Multiple Transition Abnormalities
}

National Cancer Institute

\section{Source}

National Cancer Institute. Multiple Transition Abnormalities. NCI Thesaurus. Code C45656.

Multiple point mutations in a DNA sequence from eukaryotic or prokaryotic organisms in which each mutation occurs by substitution of a purine base for a different purine base or a pyrimidine base for another pyrimidine base. These abnormalities can be either heritable or occur somatically. 